\title{
HOMENAGEM
}

\section{Paulo Vaz de Arruda - uma vida em prol da humanização no campo da Saúde}

\author{
Vera Barros de Oliveira* \\ Arthur Kaufman** \\ Marilia Martins Vizzotto***
}

A história do Dr. Paulo Vaz de Arruda confunde-se com a trajetória brasileira do ensino universitário e da prática clínica no campo da Saúde. Como relata Kaufman (2017), "Paulo nasceu em Araraquara, e foi o caçula dos 10 filhos de um agricultor. Formou-se em Medicina em 1953, e doutorou-se pela FMUSP. Ao comunicar à família que ia se tornar médico, causou espanto, pois corria à mínima alusão ao sangue, além de ter horror a hospitais. Mas maroto, engenhoso, determinado, ele já sabia que queria ser psiquiatra e que seria feliz somente se pudesse conviver com a gangorra de emoções que reflete este nosso ofício."

Em sua carreira como professor universitário e pesquisador, no início, trabalhou no Instituto de Psiquiatria do Hospital das Clínicas da Faculdade de Medicina da Universidade de São Paulo, IPq-HC-FMUSP, em 1954, tendo saído em 1998 pela Compulsória, quando foi efusivamente saudado em reunião da Congregação da Faculdade de Medicina. Foi chefe da Residência de Psiquiatria do IPq-HC-FMUSP, de 1980 a 1985. Sua trajetória mereceu amplo e profundo reconhecimento de seus pares. Kaufman, em discurso pronunciado por ocasião da cerimônia de inauguração do anfiteatro de Psiquiatria da Faculdade de Medicina de São Paulo, que passou a levar seu nome:

\begin{abstract}
"Paulo Vaz de Arruda soube manter-se moderno e atualizado durante cinco décadas de avanço da Medicina. Presto esta homenagem e este reconhecimento à personalidade e à sua obra, em meu próprio nome e em nome de todos os professores do Departamento de Psiquiatria e demais colegas do IPq que, ao reconhecerem este homem como símbolo de professor e pesquisador, decidiram ser o nome mais justo e apropriado para o local mais nobre do Instituto: Anfiteatro Paulo Vaz de Arruda." (Kaufman, 2006).
\end{abstract}

Como ressalta o autor, Paulo não se contentava apenas com a instrução, procurava a formação intelectual, cultural e humanística. $\mathrm{Na}$ seleção, via o candidato como um todo, valorizando, ao lado do conhecimento específico, seus outros aspectos. Com o entusiasmo e a competência que o caracterizavam, sempre prestou apoio aos residentes e preceptores. Ele não se contentava apenas com a instrução, procurava a formação intelectual, cultural e humanística. Com a excelência da sua didática, estímulo competente e acolhimento generoso, auxiliou vários professores na obtenção dos títulos de Doutor e Livre-Docente, como relata ainda este autor.

\footnotetext{
Doutora e Livre-Docente em Psicologia pela USP. Professora Titular da UMESP (1994-2014). Membro da Diretoria da Academia Paulista de Psicologia. Psicóloga clínica. vera.barros.oliveira@terra.com.br.

** Psiquiatra, Psicoterapeuta. Professor Doutor do Departamento de Psiquiatria da Faculdade de Medicina da Universidade de São Paulo. Rua Saint Hilaire, 87 - Jardim Paulista, São Paulo - 3885-3381.

*** Doutora em Saúde Mental, Departamento de Psiquitria da Faculdade Ciências Médicas, Unicamp Professora Titular do Programa de Pós-Graduação em Psicologia da Saúde da UMESP. mariliamartinsvizzotto@gmail.com .
} 
Foi um dos criadores do Curso Experimental de Medicina da FMUSP, uma grande inovação para a época. Naqueles anos politicamente tão conturbados, Paulo teve a ousadia, coragem e pioneirismo de implantar e coordenar o curso. Com a excelência da sua didática, estímulo competente e acolhimento generoso, auxiliou vários professores na obtenção dos títulos de Doutor e Livre-Docente. Preocupava-se com a qualidade do ensino e dedicava-se pessoalmente à formação dos professores, tendo por base um espírito democrático, pois sempre acreditou que o ensino não se coaduna com o autoritarismo.

$\mathrm{Na}$ época em que contava 40 anos, foi assistente da Clinica Psiquiátrica da Faculdade de Medicina, Chefe do Serviço de Eletroencefalografia do Hospital das Clinicas e professor de Psiconeurofisiologia da Santa Casa.

Em entrevista a peródico, ante a questão: "Durante sua história, o que foi mais gratificante em ser médico ?”, Dr. Paulo, que havia sido convidado a fazer parte de pesquisa introdutória sobre o conceito de morte cerebral, responde, lembrando que: "Quem acabou introduzindo esse conceito (de morte cerebral), para que houvesse os primeiros transplantes, fomos nós aqui dos laboratórios de psiquiatria (da FMUSP). Começamos com pesquisas em animais, e depois, com autorização do então Ministro da Justiça, passamos ao estudo com seres humanos. E não foi só um que disse: "Que maluquice é essa? A morte está aí por parada cardíaca!”. E, de repente, não mais que de repente, isso muda, você declara a morte com o coração batendo. Isso mexeu com tudo! E para se chegar nisso não foi de um dia para o outro: houve discussões com religiosos, com grandes juristas. E nós participamos dos 12 primeiros transplantes; que, infelizmente, morreram por causa do processo de rejeição." (Silva \& Aranha, s/d).

Influenciados pelos neurologistas pesquisadores norte-americanos e franceses, os doutores Paulo Arruda e Adail Julião entenderam que o registro de eletroencefalograma (EEG) evidenciava o estado comatoso. Tal como explica Kind (2007), a descrição dos franceses pioneiros em 1959 é freqüentemente mencionada como uma primeira descrição do que viria a ser denominado morte cerebral, pois o EEG com traçado plano (tracé plat à EEG) foi apontado por eles como a base para a nova definição de coma. A redefinição da morte diante dos pacientes em estado de inconsciência ligados a respiradores artificiais foi utilizada como evidência de morte. Cabe lembrar que a suspensão de recursos artificiais não representa delito contra a vida, uma vez que se trata de paciente morto, conforme explicam Santos, Moraes \&
Massarollo (2012); mas, nos anos sessenta, a legislação brasileira tinha como constante que a morte fosse dada pela parada cardíaca.

Nesse sentido, desafiando a legislação brasileira à época do regime militar, o Dr. Paulo foi um dos responsáveis por propiciar a discussão e modificação da legislação acerca da doação de órgãos no Brasil. Junto ao professor Adail de Freitas Julião, foi pela definição do conceito de morte encefálica, pela primeira vez em 1968 (Ad Hoc Committee of the Harvard Medical School, 1968). Decisão polêmica, mas, sem dúvida corajosa e incontestável, possibilitava determinar, a partir do exame eletroencefalográfico, a "comprovação de morte real", indicando a inatividade elétrica cerebral do paciente, gerando a necessidade de sistematizar, regulamentar e estabelecer critérios que definissem a morte encefálica com o intuito de impulsionar a doação de órgãos. Somente nos anos noventa, contudo, é que a legislação a respeito tornou-se efetiva (Brasil, 1997).

\section{O GRAPAL - Grupo de Assistência Psicológica ao Aluno}

Seguindo ainda com Kaufman (2006), sua preocupação profunda, vivida e constante relativa ao equilíbrio emocional dos estudantes de Medicina e demais áreas da Saúde levou-o a fundar o GRAPAL, na época em que exercia a função de coordenador das disciplinas de Psiquiatria, Psicologia Médica e Psicossomática. Paulo Vaz de Arruda tinha com os estudantes uma relação de grande proximidade: na época em que uma reunião de três pessoas já era interpretada como ato subversivo, costumava recebê-los informalmente em casa à noite, em grupos de cinco, onde se discutiam os problemas que os alunos enfrentavam na faculdade e na vida. Foi daí que nasceu a ideia de se estabelecer uma assistência psicológica aos alunos, o GRAPAL, Grupo de Assistência Psicológica ao Aluno, fundado em 1986, e que prepara os alunos às, muitas vezes, árduas e difíceis condições da Faculdade de Medicina, na época, já com mais de 15.000 atendimentos realizados.

Seu interesse para com a saúde dos estudantes e mais especificamente, a assistência psicológica ao aluno, surge bastante atrelada aos cursos de Medicina no Brasil; todavia, havia sido fortemente discutida já nos anos 1960, como menciona Paulo Vaz de Arruda em um de seus artigos, interesse esse que surgira por iniciativa de alguns professores (Milan; Marco; Rossi \& Arruda, 1999). Observa-se assim, portanto, o quanto esse médico, grande observador do comportamento e das emoções 
humanas, preocupava-se com seus alunos. Desta forma, homem de vanguarda, esteve entre os professores pioneiros na criação de um setor que cuidasse da saúde do jovem estudante.

Sua preocupação constante e atuante com o equilíbrio emocional do estudante associava-se ao equilíbrio dos profissionais de áreas da saúde, principalmente em se tratando de sua saúde mental,o que o levou a escrever vários artigos sobre essa temática. Como lembra Kaufman (2006), foi um desbravador por excelência, inclusive havendo sido pioneiro em pesquisas eletroencefalográficas, trabalhando em condições muito difíceis; publicou grande número de artigos e um deles originou uma tese para concurso de professor titular.

Dentre seus artigos, coerentes com sua visão humanista, pode ser citado o que aborda a visão biopsicossocial do ser humano e reflete sobre como a "psyché" busca essa integração (Millan, L.R.; De Marco; Rossi; Millan, M.P.B. \& Arruda, 1999). Em outro artigo, estende essa preocupação a aspectos psicológicos ligados à formaçäo médica e à assistência psicológica dada ao estudante de Medicina desde a escolha da profissäo até o final do internato, discutindo os aspectos psicológicos presentes com maior frequência em cada uma dessas etapas (Millan \& Arruda, 2008). Ainda nessa direção, busca conhecer melhor as razões e motivações que levam uma pessoa à escolha da profissão médica e escreve "What is behind a student's choice for becoming a doctor?" (Millan, L.R.; Azevedo; Rossi; De Marco; Millan, M.P. \& Arruda, 2005).

Aposentado oficialmente, continua no Centro de Desenvolvimento de Educação Médica, CEDEM, e coordenando o GRAPAL, além de prosseguir suas atividades didáticas, a partir daí na Universidade Metodista de São Paulo.

\section{Paulo Vaz de Arruda e a UMESP - suas grandes contribuições à Psicologia da Saúde}

Importante destacar que esse grande professor contribuiu enormemente para a área da Psicologia, tanto em sua dedicação ao ensino propriamente dito quanto por suas pesquisas e publicações. Foi professor titular do departamento de pós-graduação da Faculdade de Psicologia da Universidade Metodista de São Paulo, entre 1980 até 2000, no Mestrado, na época, curso stricto sensu em Psicologia da Saúde, nomenclatura por ele sugerida à professora Eda Marconi Custódio, coordenadora do curso, na época.

O Programa de Pós-Graduação em Psicologia ini- ciou suas atividades em 1978. No decorrer das décadas de 80 e 90, atento às necessidades regionais e à importância dos estudos de Psicologia e saúde, firmou-se na área de concentração da Psicologia da saúde. O programa de Pós-Graduação - Mestrado e Doutorado em Psicologia da Saúde - vinculado à Escola de Ciências Médicas e da Saúde, trata especificamente das questões comuns à Psicologia e à Saúde, definida como a aplicação dos conhecimentos e métodos da Psicologia na promoção e manutenção da saúde, na prevenção das doenças e no aperfeiçoamento do sistema de políticas públicas na área da Saúde. Assim, todo o conhecimento produzido na área de Psicologia da Saúde revelou-se importante e de interesse para toda a área da saúde e de seus profissionais.

Nele, Paulo Vaz de Arruda ofereceu disciplinas que versavam sobre a Psicossomática e o Adoecer nos Órgãos e Sistemas. Nessa proposta, trabalhava numa concepção holística sobre as concepções de que o adoecer estava inscrito numa relação sistêmica do organismo humano como um todo, de modo que as manifestações cardiovasculares, gastrintestinais, endocrinológicas, por exemplo, viessem a ser possíveis formas de perturbações homeostáticas. Incluía ainda a influência psicossocial na eclosão das neoplasias e doenças relacionadas às deficiências imunológicas. Trabalhou ainda com o desenvolvimento de pesquisas com seus alunos, tais como: "Estudo de novas técnicas de condicionamento bio-elétrico-cerebral"; "Alternância de síndromes e sintomas em psicossomática".

$\mathrm{Na}$ Metodista, entre outras publicações, escreveu extenso e profundo capítulo sobre as "Vicissitudes por que passam os profissionais da saúde em sua formação" (Arruda, 2003), para o livro sobre Psicologia da Saúde, coletânea organizada por seus pares, professores do Mestrado. Inicia seu texto lembrando que "Os diferentes profissionais da saúde, durante seu período de formação, passam por uma série de percalços, que de um modo geral, assemelham-se muito entre si." Desta forma, logo de início, evidencia sua visão integrada dos profissionais da Saúde, assim como, deixa claro que fará uso de sua larga experiência nesse campo, no terreno da Medicina, junto aos estudantes de Psicologia, resguardando, é claro, suas especificidades. Alerta para o risco de o professor se sentir e se colocar como detentor de todo saber, mas escreve que "A maneira correta é a de uma reciprocidade desta relação: ensinando, o professor continua a aprender" e, mais adiante, "A relação professor-aluno está doente, precisamos resgatá-la para resgatar a relação terapeuta-paciente, também adoecida." Lembra-nos da grande importância da imagem do professor para o 
aluno, modelo que permanece por vezes, mais forte que o conhecimento em si.

Em outro tópico, reafirma a importância da psicanálise na relação professor-aluno. Salienta a relevância da autoestima como motor da aprendizagem, ajudando o aluno a, gradativamente, ir substituindo o princípio do prazer pelo da realidade, conquista esta, difícil e sofrida, mas essencial à sua prática futura, seja no ensino, seja na clínica, diríamos. Refere-se a Bion (1973), quando escreve "A interação entre professor (continente) e aluno (conteúdo) é uma experiência ativa, englobando o pensar, o sentir, o comunicar-se e o integrar-se".

Lembra, a seguir, que o estudante universitário é um adolescente tardio, que passa por uma sobrecarga emocional em seu processo de integração egoica. Nesse sentido, tece uma crítica a escolas vinculadas à saúde, as quais preparam currículos que não valorizam elementos psicológicos. E aqui, vê-se claramente, a real e profunda importância que conferia à Psicologia, e, em particular à psicanálise. Ilustrando sua crítica, Paulo Vaz de Arruda registra, para exemplificar, que a disciplina de Psicologia em Medicina possui uma carga horária reduzida e, quase sempre, mal situada nos anos de formação.

Por outro lado, menciona Kaufman (1992), o despreparo didático de alguns professores é desproporcional ao seu saber científico.

A difícil relação estudante-paciente também é abordada longamente por Dr. Paulo, que lembra como “.... doença que o aluno se propõe a curar, como motivo principal de seu ingresso nas Faculdades ligadas à saúde, terá significado emocional diverso de acordo com as vivências anteriores que este aluno possa ter passado durante sua vida pregressa... O aluno, ao iniciar o contato com o paciente, traz consigo uma série de temores justificáveis que podem advir de sua própria insegurança pessoal". Nesse sentido, alerta para a conveniência de procurar desenvolver nos alunos não apenas conceitos teóricos e noções de práticas profissionais, mas, principalmente, buscar fazer com que compreendam a complexidade e a riqueza da relação terapeuta-cliente.

A seguir, aborda a ética no ensino, sublinhando seu papel na relação professor-aluno, a qual pode, inclusive, favorecer a qualidade do ensino, podendo e devendo ser vista em relação à ética do aluno para com o professor. Complementa abordando a ética na pesquisa e no relacionamento aluno-aluno. Como se acompanha até aqui, a leitura de Paulo Vaz de Arruda do ambiente de ensino em áreas da Saúde supõe propiciar, além de uma forte base teórica, um amadurecimento pessoal de seus atores, professores e alunos, no sentido de uma formação integrada, cognitiva, afetivo-emocional e ética.

Essa preparação torna-se relevante no momento em que o aluno inicia sua prática junto ao paciente e passa a vivenciar o fato de que uma ação terapêutica se estende ao ato de cuidar de alguém, de servir e de ter apreço por esta pessoa que está sofrendo. Nesse sentido, registra como o trabalho de equipe vinha já ganhando terreno em diversos centros universitários, com grupos de trabalho interdisciplinar dando suporte a seus membros.

Coerente a essa visão, Paulo Vaz de Arruda, assim como na FMUSP, na UMESP, manteve um relacionamento com seus colegas professores e com seus alunos de Psicologia, sempre pautado pela cordialidade, e, com alguns, mesmo, de afeto.

Agora gostaria de dar um depoimento pessoal, meu, Vera Barros, do quanto foi rico e prazeroso seu convívio na Metodista. Paulo entendia muito de psicanálise e era bom trocar ideias com ele sobre pesquisas ou alguns casos clínicos. Em certa ocasião, tive o privilégio de dar uma aula em conjunto com ele, gerada por uma situação peculiar, como explico a seguir. Nossas aulas eram às 3as. feiras, uma em seguida à outra, mas a sala era a mesma. Eu dava aula primeiro, sobre processos simbólicos. A porta de nossa sala dava para o corredor e tinha um visor na parte superior. Paulo era baixinho e, temendo que eu atrasasse, o que era raríssimo, ficava às vezes passando de um lado para o outro, no corredor, na ponta dos pés e olhando pelo vidro para dentro da sala. Era divertido, parecia um pai à espera do nascimento do primeiro filho. Um dia, resolvi convidá-lo a entrar e darmos uma aula juntos, ao que ele aceitou. Essa cooperação improvisada acabou gerando uma aula de Psicologia da Saúde muito boa, pois Paulo, para minha surpresa e encanto, tratou dos grandes sofrimentos e alegrias do psiquismo por meio de versos, que ele sabia de cor e que declamava com grande verve. Em seguida a cada poema, comentávamos e, aos poucos, todos juntos, alunos e professores íamos tecendo a rede simbólica e profunda que unia os poemas à teoria psicológica.

A seguir, são transcritos dois depoimentos clínicos que falam bem de sua imensa capacidade de ouvir e querer bem:

\footnotetext{
"Paulo Vaz de Arruda era um médico psiquiatra de qualidades excepcionais. A cada cliente cativava com sua expressão de cuidadoso carinho sempre acompanhado do seu humor infalível o que tornava a conversa amena, honesta e de franca abertura refletida, na sua expressão,
} 
com o infalível bigode a la Salvador Dali. Foram muitos os seus clientes que obtiveram dele tranquilidade e segurança em saber e poder enfrentar os desvanecimentos da vida. Além do estilo de chamar a todos de "meu nego", assim, logo no início da conversa, eliminava qualquer constrangimento e a conduzia com liberdade, paciência e atenção. Nós, que convivemos com ele, temos o sentimento de eterno agradecimento pelos conselhos e orientações recebidas que deixaram uma marca indelével em nossas vidas. Deixou saudades." PHSF - iniciais mantidas a pedido do depoente.

"Na minha primeira consulta com o Dr. Paulo, para demonstrar minha angústia, dei a ele um exemplo. Disse que quando eu procurava uma tesoura em casa, sempre deixava a gaveta da tesoura como o último lugar a ser remexido. Assim, eu poderia, por acaso, encontrá-la em algum outro lugar antes de ter que chegar onde ela teria a obrigação de estar, pois se ali não estivesse, meu desespero aumentaria e a esperança de achá-la em outro lugar, tendo sempre a última gaveta como segurança, de certa forma parecia amenizar meu sofrimento. Então ele me disse 'aqui você vai encontrar centenas de últimas gavetas'. Isso me tranquilizou muito e eu compreendi que havia começado a trilhar o caminho certo para minha cura."

Assim era o Paulo, que os clientes compreendiam, admiravam, confiavam e queriam tanto bem! Assim também foi o Paulo educador, colega de trabalho, parceiro e amigo, inteligente, sensível, vibrante. A ele, nossa homenagem profunda e sincera.

Paulo Vaz de Arruda faleceu em dezembro último, 2016. Em discurso proferido na ocasião da missa rezada ao sétimo dia de sua morte, Arthur Kaufman (2017) fez uma analogia de sua vida com a obra Madadayo de Akira
Kurosawa. Façamos dessas palavras aquelas de todos nós - alunos e colegas: "O velho professor vive como um jovem que envelhece sem perceber, nunca perdendo o senso de humor e a vontade de viver".

\section{Referências}

Ad Hoc Committee of the Harvard Medical School. (1968). Committee of the Harvard Medical School to Examine the Definition of Brain Death. A definition of irreversible coma. Report. JAMA, 205(6).

Arruda, P.C.V. (2003). Vicissitudes por que passam os profissionais da saúde em sua formação. In: V.B. Oliveira \& K. Yamamoto (Orgs.). Psicologia da Saúde: temas de reflexão e prática. São Bernardo do Campo: Universidade Metodista de São Paulo.

Bion, W.R. (1973). Atenção e interpretação: uma aproximação científica à compreensão interna na psicanálise e nos grupos. Rio de Janeiro: Imago.

Brasil (1997). Lei n ${ }^{\circ} 9.434$, de 04 de fevereiro, que dispõe sobre a remoção de órgãos, tecidos e partes do corpo humano para fins de transplante e tratamento em decorrência de morte encefálica. Disponível em: $<\underline{\text { http:// }}$ www.planalto.gov.br/ccivil 03/leis/L9434.htm>. Acesso em 17 fev 2017.

Kaufman, A. (1992). Teatro Pedagógico: bastidores da iniciação médica. São Paulo: Ágora.

Kaufman, A. (2006). Discurso proferido por ocasião da inauguração do Anfiteatro Paulo Vaz de Arruda, no IPq-HC-FMUSP, em $01^{\circ}$ de fevereiro.

Kaufman, A. (2017). Discurso proferido por ocasião da missa de sétimo dia de Paulo Vaz de Arruda, na capela do Colégio São Luís, em 04 de janeiro.

Kind, L. (2007). Morte e vida tecnológica: emergência de concepções de ser humano na história da definição de morte cerebral. Tese (doutorado em Saúde Coletiva), Ciências Humanas e Saúde. Instituto de Medicina Social da Universidade do Estado do Rio de Janeiro.

Millan, L.R.; De Marco, O.L.N.; Rossi, E.; Millan, M.P.B. \& Arruda, P.C.V. (1999). Alguns aspectos psicológicos ligados à formação médica. In: L.R. Millan; O.L.N. De Marco; E. Rossi; M.P.B. Millan \& P.C.V. Arruda. O Universo Psicológico do Futuro Médico. São Paulo: Casa do Psicólogo.

Millan, L.R. \& Arruda, P.C.V. (2008). Assistência psicológica ao estudante de Medicina: 21 anos de experiência. Revista da Associação Médica Brasileira, 54(1), 90-94

Millan, L.R.; Azevedo, R.S.; Rossi, E.; De Marco, O.L.; Millan, M.P. \& Arruda, P.C.V. (2005 Abr). What is behind a student's choice for becoming a doctor? Clinics (São Paulo), 60(2), 143-50.

Santos, M.J.; Moraes, E.L. \& Massarollo, M.C.K.B. (2012). Comunicação de más notícias: dilemas éticos frente à situação de morte encefálica. $\mathrm{O}$ mundo da saúde, 32(1), 34-40.

Silva, D.B. \& Aranha, M.R. (s/d). Entrevista concedida pelo Prof. Dr. Paulo Vaz de Arruda. Medicina e Humanidades. Histórias de Médicos. Edição 2. Disponível em: < http://med.fm.usp.br/pac/hum/humhistorias2.asp $>$. Acessado em 02 mar 2017. 